University of Wollongong

Research Online

Faculty of Informatics - Papers (Archive)

Faculty of Engineering and Information

Sciences

2007

\title{
Business and IT alignment with SEAM for enterprise architecture
}

\author{
Alain Wegmann \\ Ecole Polytechnique Fédérale de Lausanne \\ Gil Regev \\ Ecole Polytechnique Fédérale de Lausanne \\ Irina Rychkova \\ Ecole Polytechnique Fédérale de Lausanne \\ Lam-Son Le \\ Ecole Polytechnique Fédérale de Lausanne, lle@uow.edu.au \\ Jose Diego de la Cruz \\ Ecole Polytechnique Fédérale de Lausanne
}

See next page for additional authors

Follow this and additional works at: https://ro.uow.edu.au/infopapers

Part of the Physical Sciences and Mathematics Commons

\section{Recommended Citation}

Wegmann, Alain; Regev, Gil; Rychkova, Irina; Le, Lam-Son; de la Cruz, Jose Diego; and Julia, Philippe:

Business and IT alignment with SEAM for enterprise architecture 2007.

https://ro.uow.edu.au/infopapers/3687

Research Online is the open access institutional repository for the University of Wollongong. For further information contact the UOW Library: research-pubs@uow.edu.au 


\title{
Business and IT alignment with SEAM for enterprise architecture
}

\author{
Abstract \\ To align an IT system with an organization's needs, it is necessary to understand the organization 's \\ position within its environment as well as its internal configuration. In SEAM for enterprise architecture \\ the organization is considered as a hierarchy of systems that span from business down to IT. The \\ alignment process addresses the complete hierarchy. We illustrate the use of SEAM for enterprise \\ architecture with an example in which a new hiring process and an IT system are developed. With this \\ approach it is possible to train new engineers in the design of business and IT alignment. It is also \\ possible to scope projects in a way that integrate both business and IT strategies. This enables the \\ consideration of IT developments in an enterprise-wide context. \\ Disciplines \\ Physical Sciences and Mathematics \\ Publication Details \\ Wegmann, A., Regev, G., Rychkova, I., Le, L., Cruz, J. \& Julia, P. (2007). Business and IT alignment with \\ SEAM for enterprise architecture. 11th IEEE International Enterprise Distributed Object Computing \\ Conference, EDOC 2007 (pp. 111-121). Piscataway, New Jersey, USA: IEEE.
}

\section{Authors}

Alain Wegmann, Gil Regev, Irina Rychkova, Lam-Son Le, Jose Diego de la Cruz, and Philippe Julia 


\title{
Business and IT Alignment with SEAM for Enterprise Architecture
}

\author{
Alain Wegmann ${ }^{1}$, Gil Regev ${ }^{2}$, Irina Rychkova ${ }^{3}$, Lam-Son Lế ${ }^{4}$, Jose Diego de la Cruz \\ Philippe Julia ${ }^{6}$ \\ ${ }^{1-5}$ Ecole Polytechnique Fédérale de Lausanne (EPFL), School of Communication and \\ Computer Science, CH-1015 Lausanne, Switzerland \\ ${ }^{6}$ Cambridge Technology Partners, CH- 1214 Geneva, Switzerland \\ \{1alain.wegmann@epfl.ch, ${ }^{2}$ gil.regev@epfl.ch, ${ }^{3}$ irina.rychkova@epfl.ch, ${ }^{4}$ lam-son.le@epfl.ch, \\ josediego.delacruz@epfl.ch, ${ }^{6}$ philippe.julia@ctp.com?
}

\begin{abstract}
To align an IT system with an organization's needs, it is necessary to understand the organization's position within its environment as well as its internal configuration. In SEAM for Enterprise Architecture the organization is considered as a hierarchy of systems that span from business down to IT. The alignment process addresses the complete hierarchy. We illustrate the use of SEAM for Enterprise Architecture with an example in which a new hiring process and an IT system are developed. With this approach it is possible to train new engineers in the design of business and IT alignment. It is also possible to scope projects in a way that integrate both business and IT strategies. This enables the consideration of IT developments in an enterprise-wide context.
\end{abstract}

\section{Introduction}

One important quality that managers expect from IT systems is their alignment with the business and with the organizational imperatives of their company. Enterprise architecture (EA) is a discipline that addresses these issues. In this paper we present how an approach based on enterprise architecture can lead to better business and IT alignment. The approach we present is SEAM for Enterprise Architecture. We illustrate its application with an example we developed in collaboration with Cambridge Technology Partners ${ }^{1}$ (CTP), a consulting company. CTP is a software development company active in multiple market segments (e.g. e-government, financial services, etc).

SEAM (Systemic Enterprise Architecture Methods) is a set of systemic methods that addresses business (SEAM for Business) [20], enterprise architecture
(SEAM for Enterprise Architecture) and software development (SEAM for Software) [18]. These three methods share a common approach to system design [17]: they are based on General Systems Thinking [23] and on RM-ODP part 2 [7]. SEAM is mainly applied in marketing and in business and IT alignment courses for computer science graduate students [21].

The concept of system is central to the SEAM methods. The term system designates any entity that can be seen as a whole or as a composite. Hence, a market segment, a value network, a company or an IT system can all be modeled as systems. In each one of the SEAM methods we consider only the systems relevant to its particular audience. In SEAM for Business we model market segments, value networks and companies. In SEAM for EA we add, people, IT systems and - possibly - software applications to these models. In SEAM for Software we consider IT systems, software applications, software components and programming classes. Each system can be analyzed as a whole or as a composite. For example, a company can be modeled as a whole, showing its externally visible properties (e.g. service provided to its partners and to its customers, or its revenue), or as a composite (e.g. employees and IT systems within the company). Even if all methods are based on the same system modeling ontology, each one has specific heuristics depending on the application domain. For example in SEAM for Business and SEAM for EA we explore outsourcing strategies. In SEAM for Software we consider software distribution strategies.

\footnotetext{
${ }^{1}$ www.ctp.com
} 


\section{(a) Service View(s)}

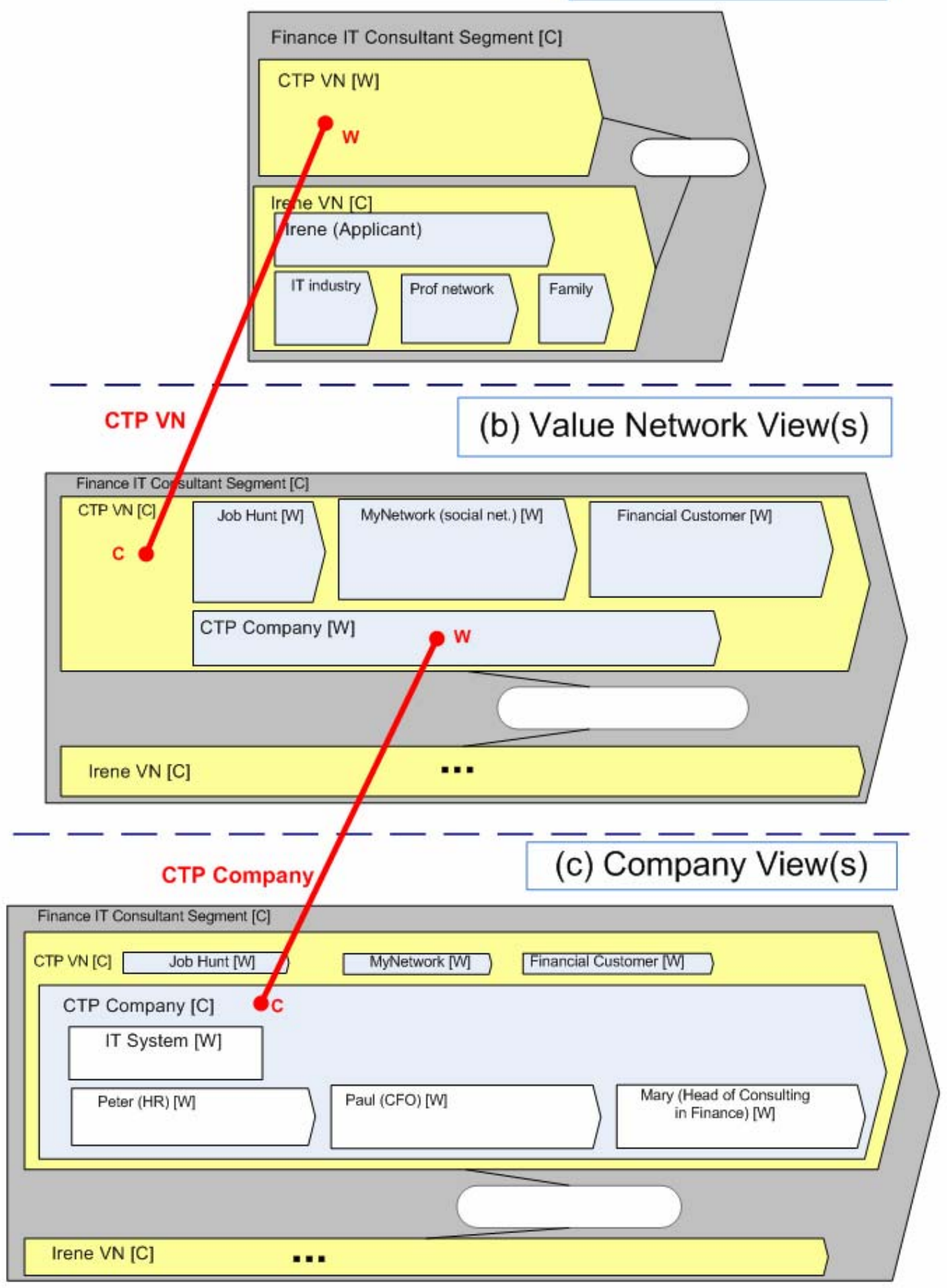

Figure 1: Set of views (a) service view(s), (b) value network view(s), (c) company view(s) that represent the system hierarchy in the enterprise model. 
The example we present is a project in which the goal is to automate the hiring process of new employees. The model we present was developed in the early requirement phase of a real project at CTP. The implementation has not been realized yet.

In Section 2 we describe the hierarchy of systems that comprise the enterprise model and explain the different views on this hierarchy. In Section 3, we present the service views; in Section 4, the supplier value network views; and in Section 5, the company views. In Section 6, we discuss some of the key principles underlying SEAM for EA. In Section 7, we present the related work

\section{The Enterprise Model as Hierarchy of Systems}

Our goal with SEAM for Enterprise Architecture is to provide a tool for reasoning about alignment between business and IT. To do so, the designers (typically working as a multi-disciplinary team) develop an enterprise model that describes the organization of interest, its internal configuration and its environment. This description is done with a hierarchy of systems as illustrated in Figure 1. To develop the enterprise model, the designers use a modeling tool that stores the enterprise model. The designers edit the model by interacting with views that the tool generates from the model. Figure 1 shows the outlines of the views presented in this paper. The choice of the views and their names depend on the project goal.

The service view $(s)$ represent the services provided by the supplier value network (i.e. the company of interest and its partners) to the adopter value network (i.e. the applicant and its partners). Figure 1a illustrates the systems represented in the service view(s). In our case, it is the service provided by the CTP value network to the prospective applicant and its partners. This view is useful to understand how the beneficiary of the service can be best served. This view abstracts away the specific role of the companies who provide the service (i.e. CTP and CTP's partners) but represents only the net effects - as a service - of their collaboration.
The supplier value network views represent the CTP Company and its partners (Figure 1b). All together, they compose the supplier value network represented, as a whole, in the first view. The goal here is to describe the responsibilities of each company. In this model, the employee and the IT systems in the company are abstracted away. Only the net effects of their collaboration are represented.

The company views represent the people and IT systems that compose the company (Figure 1c). The goal is to define the responsibility of the employees and of the IT system. The details of the construction of the IT system are abstracted away.

Additional views can be added, such as the IT views that represent the interactions between the IT modules (IT components, web services, etc) necessary to implement the IT system defined in the previous view.

When describing the views, we reason with instances of the systems (e.g. "Irene" instead of "applicant", "CTP" instead of "consulting company"). This makes the model significantly more concrete. It helps designers to think in terms of scenarios [2].

\section{Analysis and Design of Service to Customer}

The service views are used to conceptualize the business context of the project. The systems considered in this level are: the main supplier value network (considered as a whole), and the adopter value network (considered as a composite). If necessary, competing supplier value networks and segment regulators can be added [20]. Examples of regulators are: government and standardization organizations. A value network [15] is a group of organizations that share a common interest. In our example, the main supplier value network represents CTP and its partners (e.g. Job Hunt, MyNetwork). They share a common interest: hiring employees. The adopter value network represents the applicant and its partners (typically the applicant's family, the IT industry and the applicant's professional network). The applicant and its partners in the adopter value network have a common interest: a successful professional life combined with an enjoyable private life. 


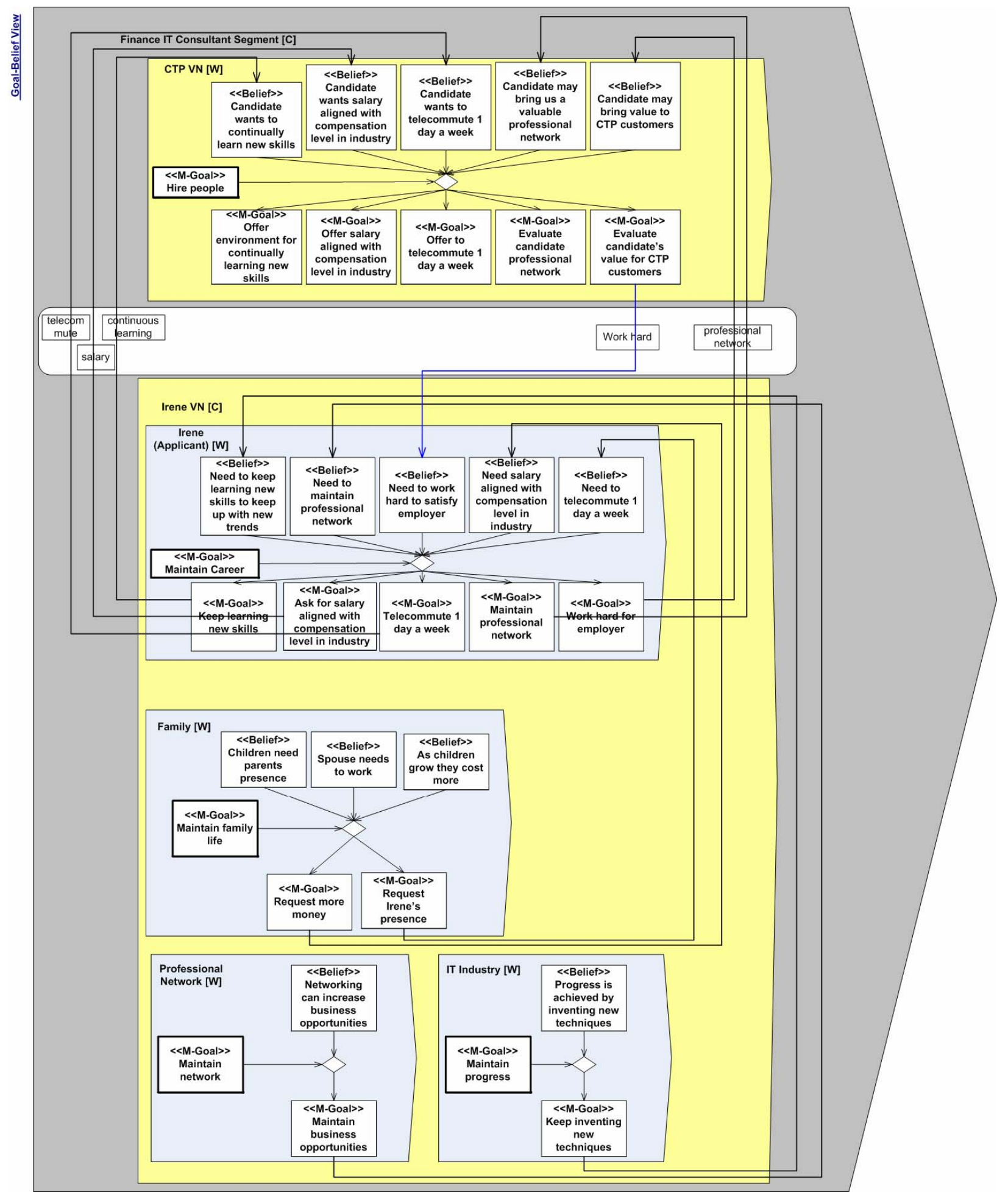

Figure 2: Goal-belief view of CTP value network (as a whole) and Irene value network (as a composite) 
The CTP value network is considered as a whole; this abstracts the internal collaboration between CTP and its partners. Only the overall service to the adopter value network is analyzed. The applicant value network is composite: the applicant and its partners are considered individually. It is useful to consider the details of the adopter value network to reason on how each member of the adopter value network benefits from the services offered by the supplier value network. Hence, it is possible to understand what CTP and its partners provide as services to the applicant and its partners.

To perform the service analysis, the designers analyze the goals and beliefs of all the systems represented in the view [13]. Figure 2 graphically represents the goals and beliefs of the supplier value network (as a whole) and of the members of the adopter value network. It also makes explicit the way they influence each other. This modeling technique is useful to discover the needs and expectations of each system. It is also useful for identifying relevant partners that could have been missed.

In our example, Irene is the main adopter. She is the applicant for a position. Irene's goals depend on her understanding of her partners in the value network: they are her family, the IT industry and her professional network. Figure 2 shows the goals and beliefs of Irene and her partners, both represented as wholes (e.g. the members of Irene's family are not represented). For example, Irene's family goal is to have Irene earn more money. This is the consequence of the belief that children cost more as they grow up. Another goal is that Irene's presence at home is required. This is the consequence of the beliefs that Irene's spouse also works and that children need their parents' presence. These family goals then become beliefs for Irene. Her beliefs drive her goals. The same analysis can be done between Irene and the IT industry or between Irene and her professional network. This leads to Irene's goals that it is important to learn new skills all the time and to maintain her professional network. As a result, Irene has the following goals:

- Keep learning new skills

- Ask for salary aligned with compensation level in industry

- Telecommute 1 day a week

- Maintain professional network

- Work hard for employer

Note that the last goal is not issued from Irene's value network. It is related to CTP's value network that needs this service from Irene. The link is made through Irene's belief that she needs to work hard to satisfy her employer.

Irene's goals are connected to CTP's value network's beliefs and influence CTP's goals in the hiring process. These goals unsurprisingly mirror those of the applicant:

- Offer environment for continually learning new skills

- Offer salary aligned with compensation level in industry

- Offer to telecommute 1 day a week

- Evaluate candidate professional network

- Evaluate candidate's value for CTP customers

The goal-belief view is useful to understand the values involved in the exchanges between the CTP value network and Irene's value network. By understanding Irene's goals, CTP can provide a significantly more appealing offer to Irene.

To understand the values exchanged is not sufficient. It is also important to specify how the exchange is done. For this, a behavior model needs to be developed. It represents the exchanges of messages that support the exchange of values identified in the goal-belief view. Figure 3 represents this behavior. The hiring process is initiated by the CTP value network: as a result an advertisement is posted. This advertisement promotes the values defined in the goal-belief model. This interests Irene and, as a result, she files an application. The application is evaluated and a decision is given to Irene. The details of the Evaluation action are not represented. The Evaluation action is, in fact, a joint action. It is defined between CTP value network and Irene. Joint actions are useful to represent the collaboration between two or more systems (and its net effect) without detailing the specific exchanges. The joint action specifies the state of all participating systems before and after the action. The details of the action's execution and the information exchanged between the systems to fulfill the action are hidden. The concept of joint action was made popular by Catalysis [6]. In the SEAM notation, a joint action is represented by having actions with the same name in each of the participating systems (e.g. action "Evaluation" in CTP VN and in Irene as well); these actions are visually connected by a dashed line ending with dots. 


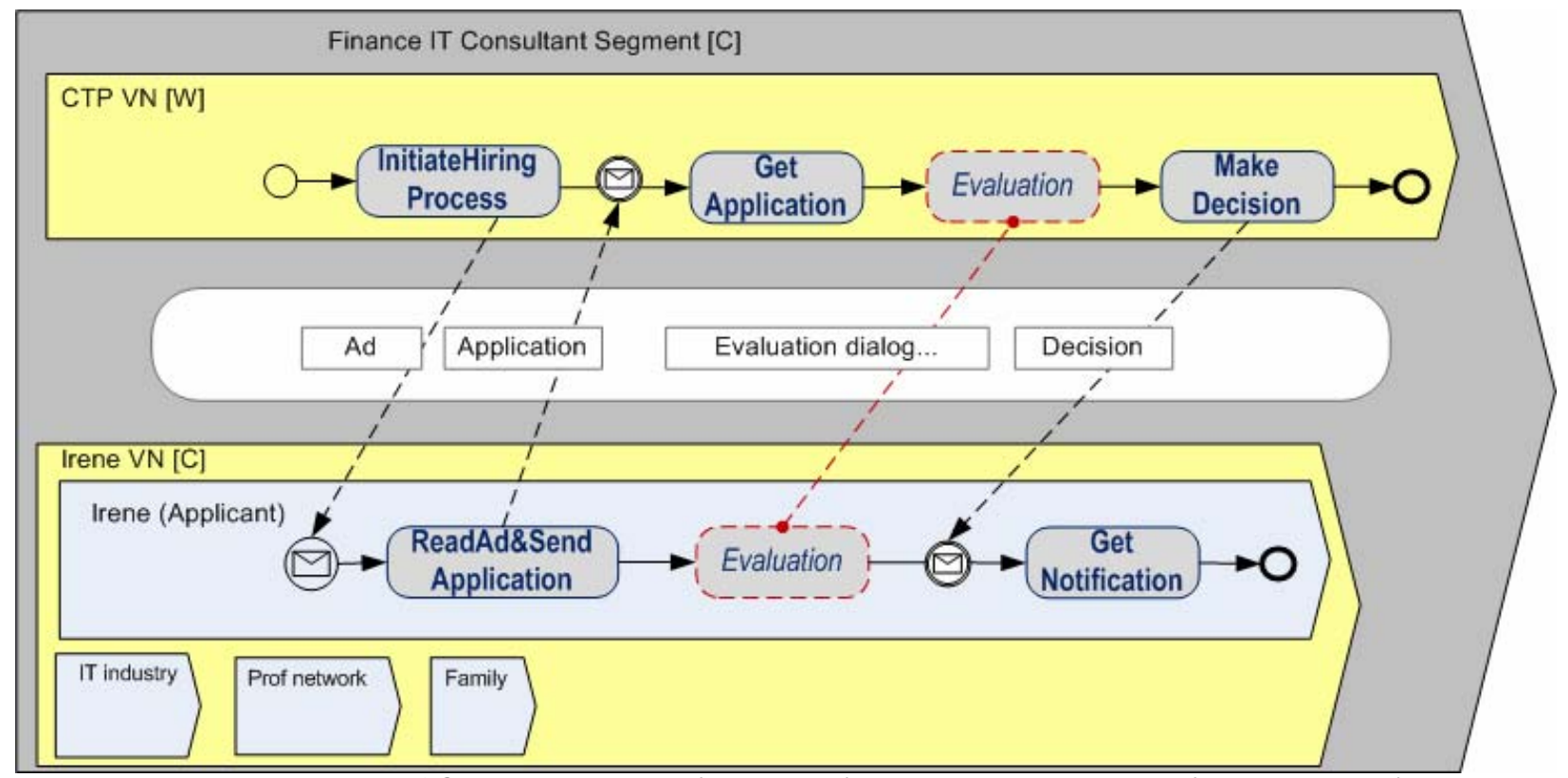

Figure 3: Behavior view of CTP value network (as a whole) and Irene value network (as a composite)

To specify the service provided by CTP VN to Irene, we have developed two views: the goal-belief view (Figure 2) and the behavior view of CTP Value Network as a whole (Figure 3). As discussed, these two views are complementary: one view defines the values exchanged and the other what concrete exchange of messages support this exchange of values. For example, the value "telecommute 1 day a week" is communicated to Irene in the "ad" message. Both views are aligned if the exchanges between the systems address all the values identified as important.

\section{Analysis of Company Responsibility and Partnership}

The value network views specify who does what in the supplier value network in order to fulfill the service described in the service view. During this analysis, the designers decide what the responsibilities of the main supplier are (CTP in our example) and what will be outsourced. They also define the inter-company business process.

First the supplier value network is represented as a composite: the companies that compose the value network are made explicit. The designers identify the main partners of CTP: a job placement company "Job Hunt", a social network management web site "MyNetwork", and a Financial Customer. The job placement company is in charge of the relations to the media (e.g. printed ads, web site). The social network management website is necessary to verify the professional network of the applicant. Financial Customer represents people who use the CTP service and who wish to be involved in the selection process to check the applicant's qualification.

Once the companies active in the CTP value network are known, the designers need to specify precisely the responsibilities of each company. This is done by distributing the tasks, defined in the hiring process described in CTP VN as a whole (Figure 3) and between the companies in the CTP VN as a composite. In Figure 4, we represent: the companies' responsibilities in the supplier value network, the outsourcing strategies, and the inter-company business process. For the sake of simplicity, we did not expand the joint actions CheckNetwork and CheckExperience. 


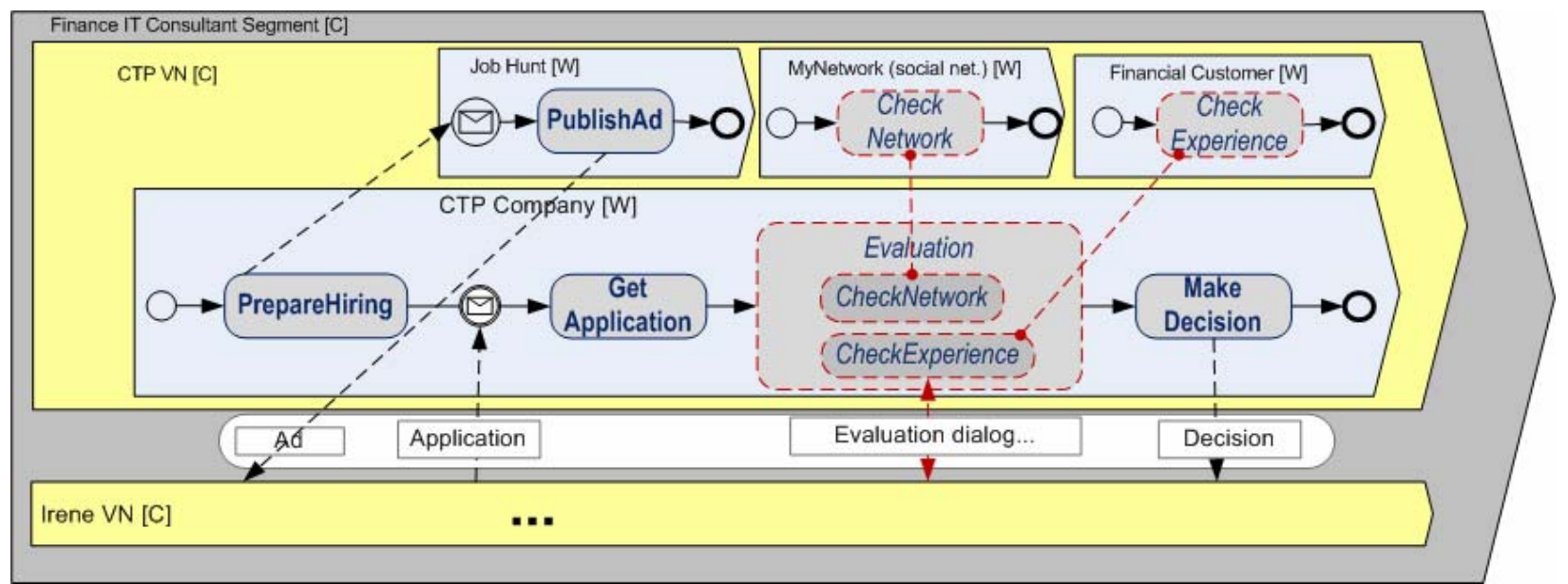

Figure 4: Behavior view of CTP value network (as a composite)

To align business and IT, we need to have an alignment between the different views of a same system. Each view represents a system specification. We define the alignment between two system specifications as the behavioral equivalence between these two systems. For example, the specification of CTP Value Network as a composite (Figure 4) is aligned with the specification of CTP Value Network as a whole (Figure 3). Both behaviors are considered equivalent as they generate the same exchanges of messages at the boundary of the CTP value network.

\section{Analysis and Design of Company's Organization}

Once the responsibility of a company is defined within its value network, it is often necessary to define the business processes within the company. This is done using the same modeling technique as previously used to model the interaction between the companies.

First the designers need to confirm the systems that exist in the company. In our example, CTP has the IT system, Peter (HR), Paul (CFO), and Mary (Head of consulting in finance) as the relevant actors in the company. Using the same principles as in Section 4, the behavior of each actor within CTP is defined (Figure 5) by distributing the tasks defined in the CTP company as a whole (Figure 4). The interactions between the people and the IT system are modeled with localized or joint actions

In our example, the business process internal to CTP is as follows: Peter, Paul and Mary initiate the hiring process. Once approved, the request to advertise the position is sent by the human resource manager (Peter) to Job Hunt to be published. Once the application is received by the IT system, the evaluation process is initiated: the human resource manager contacts the social network management web site to verify the applicant's network; the head of consulting in finance, in collaboration with the financial customer, organizes interviews for the applicant to check his/her professional experience. Afterwards, all this information is aggregated to make a decision. Once the evaluation is completed, the human resource manager enters the decision in the IT system, and the applicant is notified of the approval or rejection.

As discussed previously, the alignment between the view illustrated in Figure 5 and the view shown in Figure 4 can be verified, to ensure the overall business and IT alignment The criteria is the behavioral equivalence between CTP Company as a whole (Figure 4) and CTP Company as a composite (Figure 5). Both behaviors can be considered as equivalent because the exchanges of messages observed at the boundary of the CTP Company are the same. 


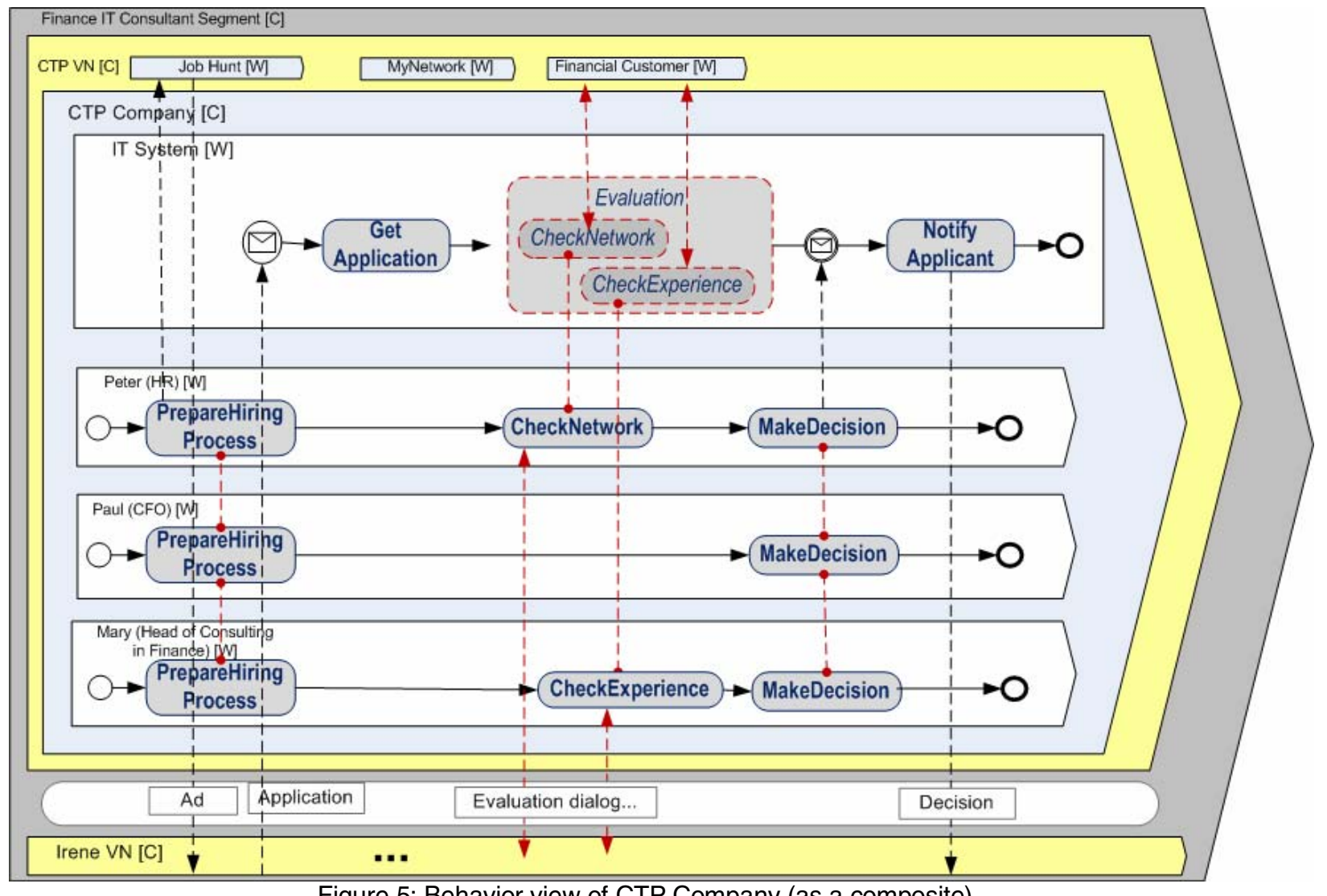

Figure 5: Behavior view of CTP Company (as a composite)

In this view (Figure 5), the intra-company business process and the roles of the different actors involved in the process are defined. The specification of the IT system is especially interesting as it defines what needs to be implemented. To define the IT system implementation, the designers need to consider the IT system as a composite. At this point, its components are visible. In our implementation, the IT system is realized by orchestrating web services. The same technique used to map the behavior between CTP value network as a whole and CTP value network as a composite or between CTP company as a whole and CTP as a composite can be used between the IT system as a whole and the IT system as a composite. The alignment between these last two specifications can then be verified (by ensuring the behavioral equivalence between them).

At this point, the specifications of the CTP Value Network as a whole and as a composite, of the CTP company as a whole and as a composite and of the IT system as a whole and as a composite are aligned. Thus we have specified an organization and an IT system that are aligned. This is how we define business and IT alignment.

\section{SEAM Principles}

With SEAM for Enterprise Architecture, the designers can run projects that span from the business down to the IT. To cover this span, the analysis and design are done across a hierarchy of systems (value network, companies, IT systems and others - if needed). Even if a SEAM analysis is hierarchical, it does not mean the world is hierarchical. It is only our perception of this world that is hierarchical. It is a convenient way to build a model that supports the overall enterprise design.

The core of SEAM is the enterprise model that represents the organization of interest, its environment and its internal configuration. The enterprise model can represent the situation as-is or the situation to-be. The different designers build and analyze the enterprise model through views that represent the part of the model relevant for them.

SEAM focuses mostly on functional analysis. Function is only one of the dimensions that we need to be considered. Financial aspects and security are examples of other dimensions. Our experience has shown that, even if limited to functionality, having a common enterprise model helps the members of a 
multi-disciplinary project team to communicate with each other and to communicate with the stakeholders not member of the team.

In SEAM we place an emphasis on the properties of a well-built enterprise model and not on the process of building it. We leave the modelers free to use any processes but we insist on the qualities of the result. The only task that is prescribed is to agree on which systems to consider. This has to be one of the first tasks of the project. Once this is done, the different specialists (marketing, business process, IT) can work in parallel or sequentially. Projects typically have short iterations that span across all levels. The model is complete when the views are aligned and when they represent the necessary information to achieve the goal of the project.

One of the originalities of SEAM is the modeling ontology. Our ontology is based on RM-ODP part 2 [7]. It is explained and illustrated in detail in [22]. The two key features of the SEAM modeling ontology are systemic and systematic. The ontology is systemic because of the importance we give to system-related concepts. For example, we make explicit in which context the concepts are defined, the boundaries of the systems, the life cycle of the systems. Our ontology is also systematic because we use the same concepts to represent business systems, as well as IT systems. As a result, our ontology is built to provide the concepts necessary to validate the alignment between the different views of the systems and, as a result, thus support business and IT alignment.

SEAM models can be developed using paper (in workshops) and computer-based modeling tools [10] (for project documentation).

The SEAM methods have been developed since 2000. SEAM is mainly used for teaching marketing and enterprise architecture [21] to computer science master's students. They are also used for consulting [19]. SEAM is well adapted for teaching as it provides a systematic method to link business design and IT design. As the same fundamental concepts are used in all disciplines, it is possible to address, with enough depth, business and IT in a course that lasts only one semester. In consulting, versions of SEAM that use a lighter notation are used to scope projects. SEAM makes possible short workshops that allow a project team to define the scope of a project and to investigate different possible solutions. Once a solution is selected, traditional modeling and development techniques are used. So SEAM is best fitted for the early requirement phases.

\section{$7 \quad$ Related Work}

The originality of SEAM is to model enterprises from business down to IT. The related work reflects the broadness of the SEAM application domain. It includes methods developed in requirements engineering, business modeling, business process modeling, enterprise architecture, computer integrated manufacturing and system modeling.

Many goal-oriented methods have been proposed in requirements engineering. The closest to SEAM goal-belief modeling is $i^{*}$ [24]. The originality of SEAM is the explicit and systematic modeling of beliefs as the motivating factor behind goals and as influences between systems.

The Business Motivation Model (BMM) was proposed by the OMG [12] in the field of business modeling. BMM introduces many popular business concepts, such as mission, vision, goals, objectives, strategy, tactic, business rule risks, reward, competitors, regulators, etc. These concepts are packaged in 6 categories: Ends, Means, Course of Action, Directive, Influencers, and Assessment. Although, its scope is comparable to SEAM, BMM appears to have many more concepts than SEAM and a less developed graphical notation.

Much work has been done on business process modeling. A method close to SEAM is DEMO (Design \& Engineering Methodology for Organizations) [3]. DEMO is a method for (re)designing organizations. The main difference is in the ontology. DEMO's ontology is based on the Communicative Action Paradigm, and SEAM on RM-ODP. DEMO can also model enterprises across organizational levels, but it does not provide goal models. In business process modeling, an important standard is BPMN [11]. The behavior notation of SEAM is close to BPMN. BPMN focuses on behavior modeling with implicit modeling of context and data. In SEAM, processes are modeled in an organizational context and process activities explicitly consume and generate data objects. In practice, SEAM is used to scope projects. When the business processes have been modeled, they are usually transformed into BPMN with tools able to generate BPEL code.

Enterprise Architecture proposes hierarchical analysis frameworks that span the whole enterprise, from business issues down to the IT systems. The most well-known and used frameworks are the Zachman Framework for Enterprise Architecture [25] and Togaf $^{2}$. These frameworks do not propose concrete modeling notations. More recent enterprise architecture

\footnotetext{
2 The Open Group Architecture Framework (TOGAF), http://www.opengroup.org/togaf
} 
methods propose an approach similar to SEAM. A notable example is Archimate [9], which provides a method to model organizations in a systematic manner. SEAM imposes a more systemic approach. In addition, SEAM proposes goal-belief modeling which does not exist in Archimate. The ISO/IEC RM-ODP standard [7] together with the ISO/IEC 15414 standard on enterprise language [8] can also be seen as an enterprise architecture framework. RM-ODP is IT system centric (and defines views that describe the IT system). SEAM analyzes all systems (both business and IT). In SEAM, we do not place a special emphasis on the IT system; it is one among all systems.

Computer integrated manufacturing also proposes frameworks and methods such as CIMOSA; IDEF or ARIS. The Computer Integrated Manufacturing Open System Architecture (CIMOSA), also known as the ISO EN/IS 19440 standard, focuses on the modeling of processes in the context of computer integrated manufacturing projects [16]. CIMOSA proposes a way to model processes at different levels of abstraction. This is similar to the SEAM functional levels. However, CIMOSA does not have explicit organizational levels like SEAM does. IDEF (Integrated DEFinition Methods) is a set of methods that address many aspects of enterprise modeling (function, data, process, object-oriented design, and ontology). Please refer to [1] for a comparison between IDEF0 and SEAM. ARIS [14] is a widely used proprietary method that has a scope similar to SEAM.

Another stream of methods addresses system modeling. Two important methods are OPM and SysML. Object-Process Methodology (OPM) addresses the modeling of systems in general [4]. OPM has its own notation and provides a modeling tool called OpCat [5]. OPM was developed for modeling software systems and can be used to model enterprises. SEAM was designed to model enterprises and can be used to model software systems. The notations reflect these different approaches. Systems Modeling Language (SysML) ${ }^{4}$ is developed by the OMG. It is based on UML. SysML targets the design of large industrial systems (e.g. aircraft, power plants, etc.). SysML can model the context of the system to develop as well as the system itself.

In summary, compared to most of the frameworks and methods mentioned in this section, SEAM brings a more elaborate analysis of the environment (e.g. the segment and goal-belief views). It provides also a systemic and systematic ontology for system modeling (based on RM-ODP). The benefit is the ability to integrate different theories in a coherent approach.

\footnotetext{
${ }^{3}$ Integrated Definition Methods, http://www.idef.com/

${ }^{4}$ OMG System Modeling Language, http://www.sysml.org/
}

SEAM attempts to integrate them in a coherent whole. Hopefully, this enables a better alignment between the business needs (the link with the environment) and IT by leveraging the different approaches that exist.

Compared to BMM [12] and ARIS [14], SEAM has a similar scope but the contents of the methods are different.

\section{Conclusions}

This paper presented a solution to the thorny business and IT alignment problem, in the form of the SEAM for Enterprise Architecture method. We illustrated the method with the use of the running example of a hiring process in a consulting company.

SEAM is novel in the attempt made to integrate, in a coherent whole, disciplines that are generally considered independent. This integration can sometimes be difficult to accept by practitioners, trained in their specific technique. Nevertheless, it has the potential to help the members of the multidisciplinary teams to develop a better common understanding of their project.

The systemic and systematic nature of SEAM facilitates the reasoning needed for this much sought for alignment. Aspects such as using the same concepts and principles to the model business and IT aspects, the contextual modeling of business processes, the simultaneous modeling of behavior and data, and goalbelief modeling enable designers to understand the business problem to be solved and role played by the IT in this solution.

With out-sourcing and off-shoring gaining in importance, software engineers' work is shifting away from pure development towards business and IT alignment as well as IT integration (e.g., with frameworks such as Service Oriented Architecture). SEAM is a powerful educational tool to train new engineers in this alignment and integration.

In industrial projects, SEAM can bring value to brainstorming (possibly with a simpler notation) on the project scope. It enables to design the business strategy, the inter-company business processes, the intra-company business process and the IT systems. This is of great value when a multi-disciplinary team needs to cast what a new project is about. 


\section{References}

[1] Balabko, P., Wegmann, A., Ruppen, A. and Clément, N. (2005). "Capturing Design Rationale with Functional Decomposition of Roles in Business Processes Modeling". Software Process: Improvement and Practice 10(4): 379 - 392.

[2] Cooper, A., The Inmates Are Running the Asylum: Why High Tech Products Drive Us Crazy and How To Restore The Sanity, Sams Publisher, 1999

[3] Dietz, J. ,Enterprise Ontology: Theory and Methodology, Springer, 2006

[4] Dori, D.. Object-Process Methodology, A Holistic Systems Paradigm, Springer Verlag, 2002

[5] Dori, D., Reinhartz-Beger, I. and Sturm, A., OPCAT - A Bimodal CASE Tool for Object-Process Based System Development. Proceedings of 5th ICEIS, Angers, France, 2003

[6] D'Souza D. Wills. A. C., Objects, Components and Frameworks with UML: the Catalysis Approach, Addison Wesley, 1999

[7] ISO/IEC 10746-1, 2, 3, $4 \quad$ ITU-T Recommendation, X.901， X.902， X.903， X.904, "Reference Model of Open Distributed Processing", 1995-1996.

[8] ISO/IEC 15414 | ITU-T Recommendation X.911

“Open Distributed Processing-

Reference Model-Enterprise Language”, 2006

[9] Lankorst, M., Enterprise Architecture at Work, Springer-Verlag, 2005

[10] Lê, L.S. and Wegmann A., "SeamCAD: ObjectOriented Modeling Tool for Hierarchical Systems in Enterprise Architecture", 39h IEEE Hawaii International Conference on System Sciences, 2006

[11] Object Management Group (OMG), Business Process Modeling Notation (BPMN) Specification, February 2006 ,

http://www.bpmn.org/Documents/OMG\%20Final\%20

Adopted\%20BPMN\%201-0\%20Spec\%2006-02-

01.pdf, accessed August 2007.

[12] Object Management Group (OMG), Business Motivation Model (BMM) Specification, August 2006, http://www.omg.org/docs/dtc/06-08-03.pdf, accessed August 2007.

[13] Regev, G. and Wegmann, A., "Defining Early IT System Requirements with Regulation Principles: The Lightswitch Approach" on the 12th IEEE International Requirements Engineering Conference (RE04) p.144 153,2004
[14] Scheer, A. W., ARIS - Business process modeling, Springer 1999.

[15] Stabell, C. B. and Fjeldstad, Ø. D., "Configuring value for competitive advantage: on chains, shops, and network", Strategic Management Journal 19(5): p. 413 $-437,1998$

[16] Vernadat, F. B. Enterprise modeling and integration: Principles and Applications. Chapman \& Hall, 1996

[17] Wegmann, A., "On the Systemic Enterprise Architecture Methodology (SEAM)", International Conference on Enterprise Information Systems (ICEIS), Angers, France, 2003

[18] Wegmann, A, Balabko, P., Lê, L.S., Regev, G. and Rychkova, I., "A Method and Tool for Business-IT Alignment in Enterprise Architecture", CAiSE'05 Forum, 2005

[19] Wegmann A., Regev, G. and Loison B., "Business and IT Alignment with SEAM", 1st International Workshop on Requirements Engineering for Business Need, and IT Alignment (REBNITA2005), 2005

[20] Wegmann A., Julia P., Regev R., Perroud O., Rychkova I., "Early Requirements and Business-IT Alignment with SEAM for Business", Proceedings of the 15th IEEE International Requirements Engineering Conference (RE'07) Dehli, India, October 2007 (currently in 2nd review)

[21] Wegmann A.; Regev G.; de la Cruz J. D., Lê L.S., and Rychkova I, "Teaching Enterprise and ServiceOriented Architecture in Practice", in Workshop on Trends in Enterprise Architecture Research (TEAR 2007), 2007

[22] Wegmann A, Lê L.-S., Regev R., Wood B., "Enterprise Modeling Using the Foundation Concepts of the RM-ODP ISO/ITU Standard", accepted for publication in Journal of Information System and eBusiness, 2007

[23] Weinberg, G.M., An Introduction to General System Thinking, Wiley \& Sons. New York, $1975 .$.

[24] Yu, E.S.K., "Towards modelling and reasoning support for early-phase requirements engineering," Proceedings of the Third IEEE International Symposium on Requirements Engineering, Annapolis, Maryland, January 1997

[25] Zachman, J. A. "A Framework for Information System Architecture". IBM System Journal 26(3): 276292, 1987. 